\title{
DFT (B3LYP) COMPUTATIONAL STUDY ON THE MECHANISMS OF FORMATION OF SOME SEMICARBAZONES
}

\author{
Abdulfatai Siaka ${ }^{a^{*}}$, Adamu Uzairu ${ }^{b}$, Sulaiman Idris ${ }^{\mathrm{b}}$, Hamza Abba ${ }^{\mathrm{a}}$ \\ ${ }^{a}$ Department of Applied Chemistry, Federal University, P.M.B 5001, Dutsin-ma 823103, Katsina, Nigeria \\ ${ }^{b}$ Department of Chemistry, Ahmadu Bello University, P.M.B 51, Zaria 810001, Kaduna, Nigeria \\ *e-mail: fatsaadaby@gmail.com
}

\begin{abstract}
Thermodynamic and kinetic mechanisms of forming six semicarbazones have been investigated computationally by DFT B3LYP method. All the reactions proceed via two transitions and include two consecutive steps: bimolecular and unimolecular. The computed transition steps have varying equilibrium constants values, enthalpy of activation and Gibbs energy of activation, depending on the semicarbazone involved. Also depending on the semicarbazones involved some of the consecutive steps are found to have varying enthalpy of reactions and spontaneity.
\end{abstract}

Keywords: semicarbazone, kinetics, bi- and unimolecular step, transition step, spontaneity.

Received: October 2015/ Revised final: February 2016/ Accepted: February 2016

\section{Introduction}

Semicarbazones are derivatives of imines formed by a condensation reaction between ketones or aldehydes and semicarbazide. They are classified as imine derivatives since they are formed from the reaction of an aldehyde or ketone with the terminal amino group of semicarbazide, which behaves similarly to primary amines. Some semicarbazones, such as nitrofurazone and thiosemicarbazones are known to have anti-viral and anti-cancer activity, usually mediated by binding to copper or iron in cells. Many semicarbazones are crystalline solids, useful for the identification of the parent aldehydes or ketones by melting point analysis [1]. Semicarbazones show a wide range of bioactivities, and their chemistry and pharmacological applications have been extensively studied. The biological properties of semicarbazones are often related to metal ion coordination. A variety of 5-nitrofuryl semicarbazone derivatives have been developed for the therapy of Chagas disease, a major problem in the Central and the South America [2]. Antiepileptic drug search has come a long way, particularly of the last two decades. With increased understanding of the pathophysiology of epilepsy, the conventional approaches have, to a great extent, been replaced by mechanism based approaches. The last decade has witnessed the emergence of semicarbazones as potential anticonvulsant agents [3,4]. Due to their biological activity there is a huge interest in the chemistry of semicarbazones [5-7]. Dimmock et al. have reported semicarbazones as potential anticonvulsant agents. A number of aryloxy aryl semicarbazones have shown significant anticonvulsant activity [8]. Also Padeya and his co-workers have reported on the synthesis of several analogs of semicarbazones and thiosemicarbazones with anticonvulsant properties [9-11]. To the best of our knowledge, literature on theoretical or semi-empirical kinetic and thermodynamic data on the reaction mechanisms of preparation of these very important molecules is very scanty. Current study attempts to provide information in this area by using theoretical and computational methods.

\section{Computational Methods}

The computation was carried out using SPARTAN14 program suite on intel(R) CORE(TM) i5-4200U CPU @ 1.60GHz $2.30 \mathrm{GHz}$ hp computer. The geometries of the reactants, transition states, intermediates and products were optimized using Molecular mechanics to remove strain energies. This was followed by semi empirical optimizations at RM1 theory level. Finally, DFT Becke's three parameter nonlocal exchange functional with the nonlocal correlation functional of Lee, Yang, Parr (B3LYP) with 6-311+G** basis set calculations was employed. Intrinsic reaction coordinate calculation was carried out at B3LYP theory level. Furthermore, heat of formation was calculated for all the stationary points using thermochemical recipe at $\mathrm{T}_{1}$ theory level after the optimization. For equilibrium geometries and transition states, the nature of the critical points was confirmed by an analytic frequency computation, and all the transition states have imaginary frequencies. All the energy parameters of the reaction mechanisms are calculated using the reported in literature expressions. Gibbs energy change, reaction rates $(k)$ and equilibrium constants $(K)$ were calculated using the expressions (1)-(5) given below [12]:

$$
\begin{aligned}
& \Delta G_{(298.15 K)}^{\#}=\Delta H^{\#}-T \Delta S^{\#} \\
& k_{(298.15 K)}=\frac{k_{B} T}{h c^{o}} e^{\Delta S^{\# / R}} e^{-\Delta H^{\#} / R T} \\
& K_{(298.15 K)}=e^{-\Delta G^{o} / R T}
\end{aligned}
$$


$K_{(298.15 K)}=e^{-\Delta G^{o} / R T}$

$A=\frac{e^{2} k_{B} T}{h c^{o}} e^{\frac{\Delta S^{\#}}{R}}$, for bimolecular step

$A=\frac{e k_{B} T}{h} e^{\frac{\Delta S^{\#}}{R}}$, for unimolecular step

where $\Delta G^{\#}, \Delta H^{\#}$ and $\Delta S^{\#}$ stand for Gibbs energy change, enthalpy change and entropy change, respectively, for reaction between reactant(s) and a transition state, $k_{B}$ is Boltzmann's constant, $R$ is gas constant, $h$ is Planck's constant, $C^{o}$ is concentration (taken as unity), $T$ is temperature and stands for Gibbs energy change for reaction between reactant(s) and intermediate or product.

\section{Results and discussion}

\section{Reaction between m-nitrobenzaldehyde and semicarbazide}

The computed general reaction mechanism of forming the (E)-2-(3-nitrobenzylidene)hydrazinecarboxamide and water from $m$-nitrobenzaldehyde and semicarbazide is presented and discussed herein. Figures 1 and 2 show the general reaction mechanism and schematic diagram of relative electronic energy of reaction, respectively, while Tables 1 and 2, respectively, present thermodynamic and kinetic parameters of the computed reaction mechanism.<smiles>O=Cc1cccc([N+](=O)[O-])c1</smiles>

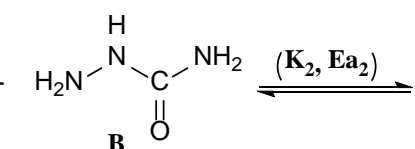<smiles>NC(=O)NNC(=O)c1cccc([N+](=O)[O-])c1</smiles><smiles>NC(=O)NN=C(O)c1cccc([N+](=O)[O-])c1</smiles>

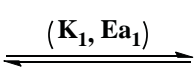<smiles>NC(=O)NNC(O)c1cccc([N+](=O)[O-])c1</smiles><smiles>NC(=O)N/N=C/c1cccc([N+](=O)[O-])c1</smiles><smiles>[3H]O[3H]</smiles>

P2

Figure 1. General scheme for the mechanism of reaction between $m$-nitrobenzaldehyde and semicarbazide.

DFT B3LYP (6-311+G**) calculated thermodynamic parameters for reaction between $m$-nitrobenzaldehyde and semicarbazide.

\begin{tabular}{|c|c|c|c|c|c|c|}
\hline Steps & $\begin{array}{c}\Delta S_{\text {reaction }}^{\#} \\
\left(\mathrm{Jmol}^{-1} \mathrm{~K}^{-1}\right)\end{array}$ & $\begin{array}{l}\Delta H_{\text {reaction }}^{\#} \\
\left(\mathrm{kJmol}^{-1}\right)\end{array}$ & $\begin{array}{c}\Delta G_{\text {reaction }}^{\#} \\
\left(\mathrm{kJmol}^{-1}\right)\end{array}$ & $\begin{array}{l}\Delta S_{\text {reaction }}^{o} \\
\left(\mathrm{Jmol}^{-1} \mathrm{~K}^{-1}\right)\end{array}$ & $\begin{array}{c}\Delta H_{\text {reaction }}^{o} \\
\left(\mathrm{kJmol}^{-1}\right)\end{array}$ & $\begin{array}{c}\Delta G_{\text {reaction }}^{o} \\
\left(\mathrm{kJmol}^{-1}\right)\end{array}$ \\
\hline $\mathrm{A}+\mathrm{B} \rightleftharpoons \mathrm{TSI}$ & -238.89 & -24.16 & +47.06 & & & \\
\hline $\mathrm{A}+\mathrm{B} \rightarrow \mathrm{INT}$ & & & & -246.60 & -40.82 & +32.71 \\
\hline $\mathrm{INT} \rightleftharpoons \mathrm{TSII}$ & +36.78 & -0.60 & -11.12 & & & \\
\hline $\mathrm{INT} \rightarrow \mathrm{P} 1+\mathrm{P} 2$ & & & & +173.30 & +9.99 & -41.68 \\
\hline
\end{tabular}

DFT B3LYP $\left(6-311+G^{* *}\right)$ calculated activation energy $\left(E_{a}\right)$, frequency factor $(A)$, rate constant $(k)$ and equilibrium constant $(K)$ for reaction between $m$-nitrobenzaldehyde and semicarbazide.

\begin{tabular}{|c|c|c|c|c|c|c|}
\hline Steps & $\begin{array}{c}E_{a} \\
\left(\mathrm{kJmol}^{-1}\right)\end{array}$ & $\bar{A}$ & $\begin{array}{c}k_{2} \\
\left(\mathrm{dm}^{3} \mathrm{~mol}^{-1} \mathrm{~s}^{-1}\right)\end{array}$ & $K_{2}$ & $\begin{array}{c}k_{1} \\
\left(s^{-1}\right)\end{array}$ & $K_{1}$ \\
\hline $\begin{array}{l}A+B \rightleftharpoons \text { TSI } \\
A+B \rightarrow I N T\end{array}$ & +55.92 & $15.26 \mathrm{dm}^{3} \mathrm{~mol}^{-1} \mathrm{~s}^{-1}$ & $3.53 \times 10^{4}$ & $1.86 \times 10^{-6}$ & & \\
\hline $\begin{array}{c}\mathrm{INTI} \rightleftharpoons \mathrm{TSII} \\
\mathrm{INT} \rightarrow \mathrm{P} 1+\mathrm{P} 2\end{array}$ & +31.24 & $1.41 \times 10^{15} \mathrm{~s}^{-1}$ & & & $5.18 \times 10^{14}$ & $2.00 \times 10^{7}$ \\
\hline
\end{tabular}


From Tables 1 and 2, the first transition step has a huge energy barrier to overcome. This step is also associated with positive Gibbs energy of activation, suggesting that the step is non-spontaneous, and so energy input is a necessity to initiate it. Meanwhile the second transition step is less demanding in terms of energy, having less activation energy, but it is also reasonably spontaneous (having negative Gibbs energy of activation). Thus, the first step is exothermic but nonspontaneous. The spontaneity barrier for this step will be overcome by the higher exothermic value of the step, making the step energetically feasible. The second step is slightly endothermic but averagely spontaneous. The first transition step is associated with less pre-exponential factor, as compared to the second step, hence supporting the low equilibrium constant computed for the bimolecular transition step and the rate determining bimolecular step. The energy profile of the reaction is shown in Figure 2.

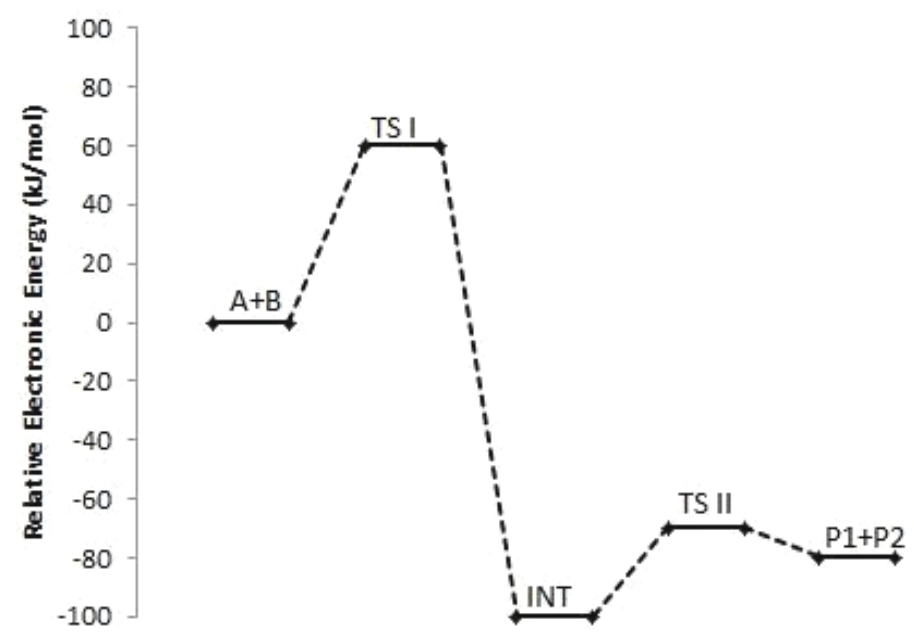

Figure 2. Diagram of relative electronic energies along the channels of the reaction between $m$-nitrobenzaldehyde and semicarbazide.

\section{Reaction between furfural and semicarbazide}

Presented as Figure 3 below is the general formation pathways for (Z)-2-(furan-2-ylmethylene) hydrazinecarboxamide and water from furfural and semicarbazide. Figure 4 shows the schematic diagram of the relative electronic energies of this reaction. Tables 3 and 4 present thermodynamic and kinetic parameters of the computed reaction mechanism, correspondingly.<smiles>O=Cc1ccco1</smiles>

A<smiles>NC(=O)NNC(N)=O</smiles>

TS II<smiles>NC(=O)NN=C(O)c1ccco1</smiles>

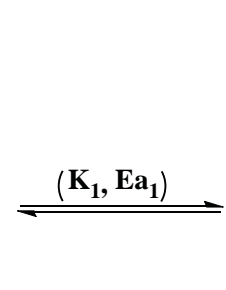<smiles>c1ccccc1</smiles><smiles>CCCC</smiles><smiles>NC(=O)N/N=C/c1ccco1</smiles><smiles>NC(=O)NNC(=O)c1ccco1</smiles>

TS I<smiles>NC(=O)NNC(O)c1ccco1</smiles>

P2

Figure 3. General scheme for the mechanism of reaction between furfural and semicarbazide. 
DFT B3LYP (6-311+G**) calculated thermodynamic parameters for reaction between furfural and semicarbazide.

\begin{tabular}{ccccccc}
\hline Steps & $\begin{array}{c}\Delta S_{\text {reaction }}^{\#} \\
\left(\mathrm{Jmol}^{-1} \mathrm{~K}^{-1}\right)\end{array}$ & $\begin{array}{c}\Delta H_{\text {reaction }}^{\#} \\
\left(\mathrm{kJmol}^{-1}\right)\end{array}$ & $\begin{array}{c}\Delta G_{\text {reaction }}^{\#} \\
\left(\mathrm{kJmol}^{-1}\right)\end{array}$ & $\begin{array}{c}\Delta S_{\text {reaction }}^{o} \\
\left(\mathrm{Jmol}^{-1} \mathrm{~K}^{-1}\right)\end{array}$ & $\begin{array}{c}\Delta H_{\text {reaction }}^{o} \\
\left(\mathrm{kJmol}^{-1}\right)\end{array}$ & $\begin{array}{c}\Delta G_{\text {reaction }}^{o} \\
\left(\mathrm{kJmol}^{-1}\right)\end{array}$ \\
\hline $\begin{array}{c}\mathrm{A}+\overline{\mathrm{B}} \rightleftharpoons \overline{\mathrm{T}} \mathrm{SI} \\
\mathrm{A}+\mathrm{B} \rightarrow \mathrm{INT}\end{array}$ & -225.75 & -12.55 & +54.76 & & -52.74 & 17.19 \\
$\mathrm{INT} \rightleftharpoons \mathrm{TS} \mathrm{II}$ & +6.66 & +4.27 & +2.28 & -234.53 & & -43.04 \\
$\mathrm{INT} \rightarrow \mathrm{P} 1+\mathrm{P} 2$ & & & & 169.80 & 7.59 & -43 \\
\hline
\end{tabular}

Table 4

DFT B3LYP (6-311+G**) calculated activation energy $\left(E_{a}\right)$, frequency factor $(A)$, rate constant $(k)$ and equilibrium constant $(K)$ for reaction between furfural and semicarbazide.

\begin{tabular}{ccccccc}
\hline Steps & $\begin{array}{c}E_{a} \\
\left(\mathrm{kJmol}^{-1}\right)\end{array}$ & $A$ & $\begin{array}{c}k_{2} \\
\left(\mathrm{dm}^{3} \mathrm{~mol}^{-1} \mathrm{~s}^{-1}\right)\end{array}$ & $K_{2}$ & $\begin{array}{c}k_{1} \\
\left(\mathrm{~s}^{-1}\right)\end{array}$ & \\
\hline $\mathrm{A}+\mathrm{B} \rightleftharpoons \mathrm{TSI}$ & 168.06 & $74.09 \mathrm{dm}^{3} \mathrm{~mol}^{-1} \mathrm{~s}^{-1}$ & & $9.75 \times 10^{-4}$ & & \\
$\mathrm{~A}+\mathrm{B} \rightarrow \mathrm{INT}$ & & & $1.58 \times 10^{3}$ & & & $3.47 \times 10^{7}$ \\
$\mathrm{INT} \rightleftharpoons \mathrm{TS}$ II & +157.01 & $3.76 \times 10^{13} \mathrm{~s}^{-1}$ & & & $2.47 \times 10^{12}$ & \\
INT $\rightarrow \mathrm{P} 1+\mathrm{P} 2$ & & & & & \\
\hline
\end{tabular}

From the high energy requirements (Gibbs energy of activation and activation energy) presented in Tables 3 and 4, the first transition step appears almost impossible without energy input into the system. Though exothermic from the enthalpy of activation value, the energy release from this step does not reach the huge energy requirement. This position is complimented by the low equilibrium constant, as presented in Table 4, suggesting some adjustment in reaction conditions for forward reaction. Similar trend is also observed in the second transition step that have high energy barrier, Gibbs energy of activation and enthalpy of activation, being also associated with low equilibrium constant. The frequency factor is indicative that only a small fraction of the reacting species is able to undergo useful collision (with required threshold energy) and finally resulting in product formation. Again the second transition step is highly demanding in energetics for forward reaction. The first step of the consecutive reaction has a very high exothermic enthalpy but slightly positive Gibbs energy of activation. This is favourable in terms of energy requirements, since the exothermic enthalpy value is much more than the Gibbs energy of reaction. Conversely, the second consecutive step is computed to be slightly endothermic but highly spontaneous. So, the energy needed for the forward reaction is compensated for by the Gibbs energy of reaction. The bimolecular step is also found to be the rate determining step. The Figure 4 shows the energy reaction profile of the reaction scheme between furfural and semicarbazide.

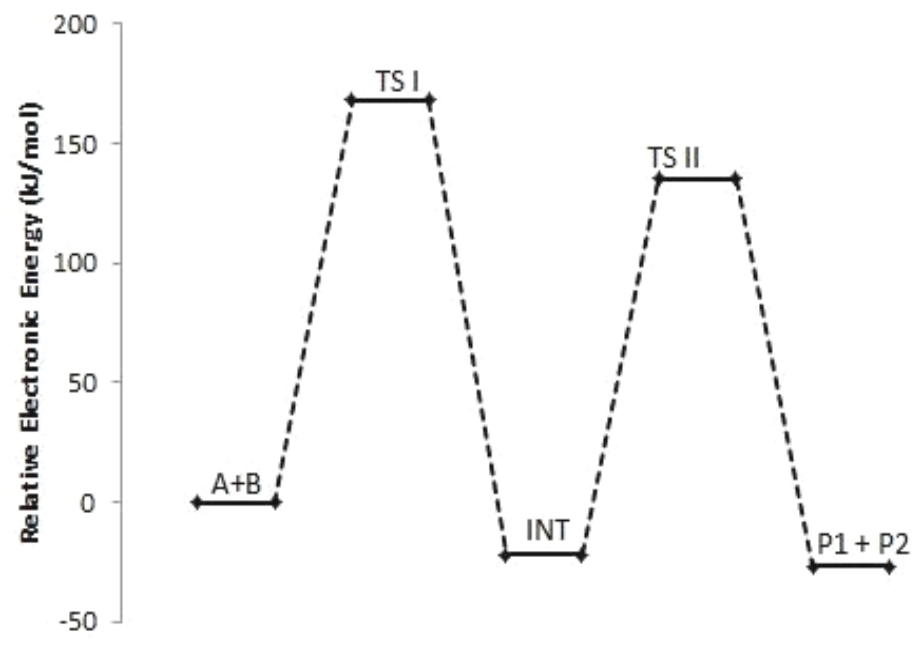

Figure 4. Diagram of relative electronic energies along the reaction channels between furfural and semicarbazide. 


\section{Reaction between p-chlorobenzaldehyde and semicarbazide}

The mechanism of synthesis of 2-((4-chlorophenyl(hydroxy)methyl) hydrazinecarboxamide and water starting from $p$-chlorobenzaldehyde and semicarbazide is schematically presented in Figure 5. Figure 6 shows the schematic diagram of the electronic energies for this mechanism of reaction. Thermodynamic and kinetic data are presented in Tables 5 and 6, respectively.<smiles>NNC(=O)NN</smiles>
A<smiles>NC(=O)Nn1c(O)cc2ccc(Cl)cc21</smiles>

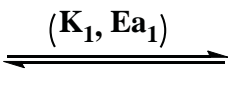<smiles>NC(=O)N/N=C/c1ccc(Cl)cc1</smiles><smiles>NC(=O)NNC(=O)c1ccc(Cl)cc1</smiles>

TS I<smiles>NC(=O)NNC(O)c1ccc(Cl)cc1</smiles>

Figure 5. General mechanism scheme for reaction between $p$-chlorobenzaldehyde and semicarbazide.

DFT B3LYP (6-311+G**) calculated thermodynamic parameters for reaction between $p$-chlorobenzaldehyde and semicarbazide.

\begin{tabular}{ccccccc}
\hline Steps & $\begin{array}{c}\Delta S_{\text {reaction }}^{\#} \\
\left(\text { Jmol }^{-1} \mathrm{~K}^{-1}\right)\end{array}$ & $\begin{array}{c}\Delta H_{\text {reaction }}^{\#} \\
\left(\mathrm{kJmol}^{-1}\right)\end{array}$ & $\begin{array}{c}\Delta G_{\text {reaction }}^{\#} \\
\left(\mathrm{kJmol}^{-1}\right)\end{array}$ & $\begin{array}{c}\Delta S_{\text {reaction }}^{o} \\
\left(\mathrm{Jmol}^{-1} \mathrm{~K}^{-1}\right)\end{array}$ & $\begin{array}{c}\Delta H_{\text {reaction }}^{o} \\
\left(\mathrm{kJmol}^{-1}\right)\end{array}$ & $\begin{array}{c}\Delta G_{\text {reaction }}^{o} \\
\left(\mathrm{kJmol}^{-1}\right)\end{array}$ \\
\hline $\begin{array}{c}\mathrm{A}+\mathrm{B} \rightleftharpoons \mathrm{TSI} \\
\mathrm{A}+\mathrm{B} \rightarrow \mathrm{INT}\end{array}$ & -235.91 & -14.04 & +56.30 & -243.19 & -32.74 & +39.77 \\
$\mathrm{INT} \rightleftharpoons \mathrm{TSII}$ & +26.99 & +6.44 & -1.61 & & & \\
$\mathrm{INT} \rightarrow \mathrm{P} 1+\mathrm{P} 2$ & & & & +171.20 & +3.01 & -48.03 \\
\hline
\end{tabular}

Table 6

DFT B3LYP $\left(6-311+G^{* *}\right)$ calculated activation energy $\left(E_{q}\right)$, frequency factor $(A)$, rate constant $(k)$ and equilibrium constant $(K)$ for reaction between $p$-chlorobenzaldehyde and semicarbazide.

\begin{tabular}{ccccccc}
\hline Steps & $\begin{array}{c}E_{a} \\
\left(\mathrm{kJmol}^{-1}\right)\end{array}$ & $A$ & $\begin{array}{c}k_{2} \\
\left(\mathrm{dm}^{3} \mathrm{~mol}^{-1} \mathrm{~s}^{-1}\right)\end{array}$ & $K_{2}$ & $\begin{array}{c}k_{1} \\
\left(\mathrm{~s}^{-1}\right)\end{array}$ & $K_{1}$ \\
\hline $\begin{array}{c}\mathrm{A}+\mathrm{B} \rightleftharpoons \mathrm{TSI} \\
\mathrm{A}+\mathrm{B} \rightarrow \mathrm{INT}\end{array}$ & +57.76 & $21.85 \mathrm{dm}^{3} \mathrm{~mol}^{-1} \mathrm{~s}^{-1}$ & & & & \\
$\mathrm{INT} \rightleftharpoons \mathrm{TS}$ II & +32.29 & $4.34 \times 10^{14} \mathrm{~s}^{-1}$ & $8.52 \times 10^{4}$ & & & \\
$\mathrm{INT} \rightarrow \mathrm{P} 1+\mathrm{P} 2$ & & & & & $1.18 \times 10^{-7}$ & $2.60 \times 10^{8}$ \\
\hline
\end{tabular}

The bimolecular transition step, though exothermic, is highly non spontaneous, and it has slightly high energy barrier to overcome. Hence energy input is necessary to kick start the reaction. The energy parameters for this step are presented in Table 5. Very small percentage of the reacting molecules possesses the threshold energy to undergo useful collision; this is evident from frequency factor and equilibrium constant values presented in Table 6 . The unimolecular transition step is calculated to be sparingly endothermic and spontaneous, as suggested by the values of enthalpy of activation and Gibbs energy of activation (Table 5). This step has relatively less activation energy to overcome, when compared to the bimolecular step, and it is also favoured more by both pre-exponential factor and equilibrium constant 
values. The first bimolecular step is found to be exothermic (by enthalpy of reaction) and non-spontaneous (by reaction free energy), indicating on the slight feasibility of this step, since the energy requirements (Table 5) for the reaction to be spontaneous are compensated for by the reaction enthalpy. Thus, bimolecular step is calculated to be the rate determining step and hence the rate determining of the overall reaction mechanism. The data for the reaction kinetics are presented in Table 6 . The unimolecular consecutive step is predominantly spontaneous and slightly endothermic by the enthalpy value. In terms of energy, this step is highly feasible, as the energy requirements for endothermicity are by far overwhelmed by the Gibbs energy of reaction. Energy reaction profile for the mechanistic scheme of reaction is shown in Figure 6.

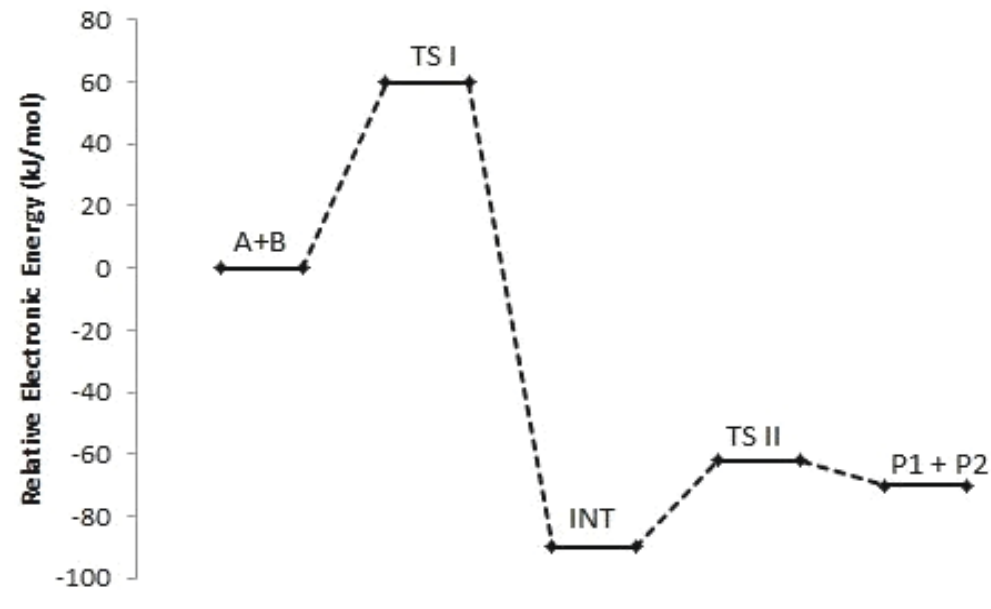

Figure 6. Diagram of relative electronic energies along the channels of the reaction between $p$-chlorobenzaldehyde and semicarbazide.

\section{Reaction between benzaldehyde and semicarbazide}

The computed mechanism of combination between benzaldehyde and semicarbazide, resulting in formation of (E)-2-benzylidenehydrazinecarboxamide and water, is shown in Figure 7, while Figure 8 presents the schematic diagram of the electronic energies for this reaction mechanism. The calculated thermodynamic and kinetic parameters are shown in Tables 7 and 8, respectively.<smiles>O=Cc1ccccc1</smiles><smiles>NNC(N)=O</smiles><smiles>NC(=O)NN1C(O)=C(c2ccccc2)C1[As]</smiles>

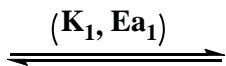<smiles>c1ccccc1</smiles><smiles>C1CC1</smiles><smiles>NC(=O)NNC(=O)c1ccccc1</smiles>

TS I

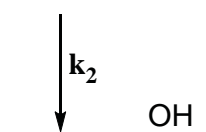<smiles></smiles>

Figure 7. General scheme for the mechanism of reaction between benzaldehyde and semicarbazide. 
DFT B3LYP (6-311+G**) calculated thermodynamic parameters for reaction between benzaldehyde and semicarbazide.

\begin{tabular}{ccccccc}
\hline Steps & $\begin{array}{c}\Delta S_{\text {reaction }}^{\#} \\
\left(\mathrm{Jmol}^{-1} \mathrm{~K}^{-1}\right)\end{array}$ & $\begin{array}{c}\Delta H_{\text {reaction }}^{\#} \\
\left(\mathrm{kJmol}^{-1}\right)\end{array}$ & $\begin{array}{c}\Delta G_{\text {reaction }}^{\#} \\
\left(\mathrm{kJmol}^{-1}\right)\end{array}$ & $\begin{array}{c}\Delta S_{\text {reaction }}^{o} \\
\left(\mathrm{Jmol}^{-1} \mathrm{~K}^{-1}\right)\end{array}$ & $\begin{array}{c}\Delta H_{\text {reaction }}^{o} \\
\left(\mathrm{kJmol}^{-1}\right)\end{array}$ & $\begin{array}{c}\Delta G_{\text {reaction }}^{o} \\
\left(\mathrm{kJmol}^{-1}\right)\end{array}$ \\
\hline $\begin{array}{c}\mathrm{A}+\mathrm{B} \rightleftharpoons \mathrm{TSI} \\
\mathrm{A}+\mathrm{B} \rightarrow \mathrm{INT}\end{array}$ & -232.78 & -24.89 & +44.51 & & -26.76 & +45.23 \\
$\mathrm{INT} \rightleftharpoons \mathrm{TS}$ II & +14.84 & -15.40 & -19.83 & -241.47 & & \\
$\mathrm{INTI} \rightarrow \mathrm{P} 1+\mathrm{P} 2$ & & & & +173.83 & +15.07 & -36.76 \\
\hline
\end{tabular}

DFT B3LYP $\left(6-311+G^{* *}\right)$ calculated activation energy $\left(E_{a}\right)$, frequency factor $(A)$, rate constant $(k)$ and equilibrium constant $(K)$ for reaction between benzaldehyde and semicarbazide.

\begin{tabular}{|c|c|c|c|c|c|c|}
\hline Steps & $\begin{array}{c}E_{a} \\
\left(\mathrm{kJmol}^{-1}\right)\end{array}$ & $A$ & $\begin{array}{c}k_{2} \\
\left(d m^{3} \mathrm{~mol}^{-1} \mathrm{~s}^{-1}\right)\end{array}$ & $K_{2}$ & $\begin{array}{c}k_{1} \\
\left(s^{-1}\right)\end{array}$ & $K_{1}$ \\
\hline $\begin{array}{l}A+B \rightleftharpoons T S I \\
A+B \rightarrow I N T\end{array}$ & +66.69 & $31.84 \mathrm{dm}^{3} \mathrm{~mol}^{-1} \mathrm{~s}^{-1}$ & $9.88 \times 10^{4}$ & $1.19 \times 10^{-8}$ & & \\
\hline $\begin{array}{c}\mathrm{INT} \rightleftharpoons \mathrm{TS} \text { II } \\
\mathrm{INT} \rightarrow \mathrm{P} 1+\mathrm{P} 2\end{array}$ & +213.72 & $1.01 \times 10^{14} \mathrm{~s}^{-1}$ & & & $1.85 \times 10^{16}$ & $2.75 \times 10^{6}$ \\
\hline
\end{tabular}

From Tables 7 and 8, the first (bimolecular) transition step has high activation energy to overcome and it is nonspontaneous too, though the step is computed to have an exothermic enthalpy of activation. The net effect is that some energy has to be supplied in order to initiate the reaction. As in the mechanisms of formation of the other semicarbazones under discussion in the current paper, the first transition step is characterized by low collision frequency factor and equilibrium constant values. These values suggest that the reaction conditions need to be adjusted for forward reaction, leading to product formation. The unimolecular transition step is calculated to be slightly spontaneous and exothermic. The energy from these spontaneity and exothermicity do not match huge activation energy demand of this step, therefore some intervention in form of energy input is necessary for the reaction to proceed. However, this step is found to be associated with high pre-exponential factor and equilibrium constant values. In the consecutive reaction steps, the unimolecular step is exothermic and non-spontaneous with energy deficit of about $20 \mathrm{kJmol}^{-1}$ (Table 7). The energy deficit in the bimolecular step is offset by the excess energy in the unimolecular step, and hence, overall, the consecutive step is feasible. In addition, the second step in the consecutive scheme is computed to be the rate determining step and the reaction rate overall.

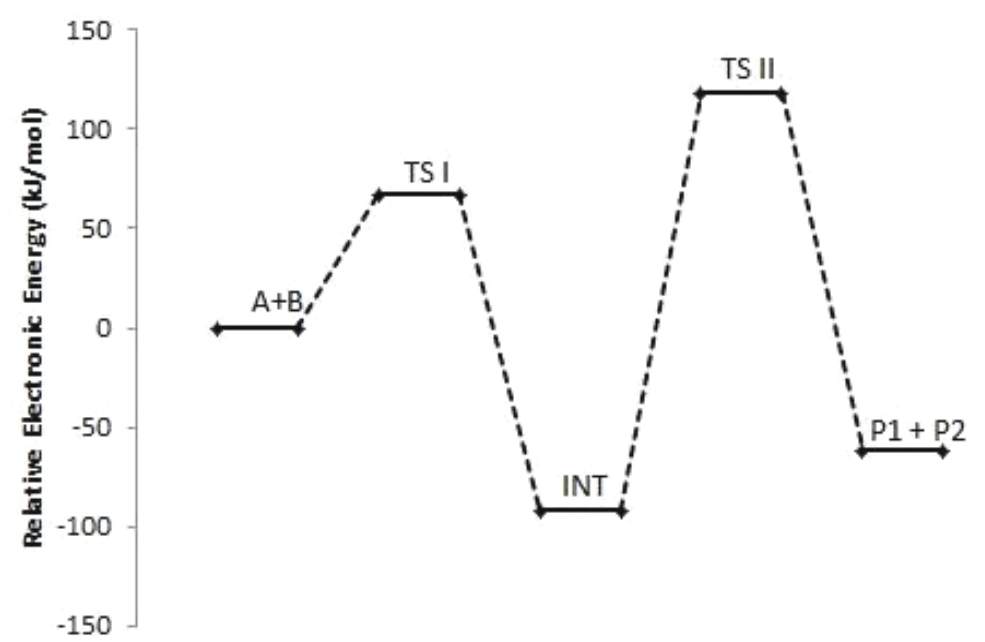

Figure 8. Diagram of relative electronic energies along the channels of the reactions between benzaldehyde and semicarbazide.

\section{Reaction between p-methylbenzaldehyde and semicarbazide}

Figure 9 illustrates the general reaction mechanism of formation of (E)-2-(4-methylbenzylidene) hydrazinecarboxamide (semicarbazone) and water, starting with $p$-methylbenzaldehyde and semicarbazide, while 
Figure10 depicts the schematic diagram of the electronic energy of the discussed reaction mechanism. Tables 9 and 10 present thermodynamic and kinetic parameters, correspondingly, for the computed mechanism.

As shown in Tables 9 and 10, the first transition step was computed to have positive activation energy and positive Gibbs energy of activation, i.e. reaction is non-spontaneous, but exothermic (from enthalpy of activation). The step has huge energy deficit of slightly above $90 \mathrm{~kJ} / \mathrm{mol}$, which need to be supplied in order to initiate the reaction. The step is calculated to have very low frequency factor and small equilibrium constant values, also suggesting some adjustment in the reaction conditions to favour forward reaction. Furthermore, the second transition step is found to be hugely demanding in terms of energy, as it is calculated to have high energy barrier, and be highly non-spontaneous (from Gibbs energy of activation) and also endothermic (from enthalpy of activation) values. The first bimolecular step is exothermic and non-spontaneous, with an energy deficit as presented in Table 9. The second consecutive step is slightly exothermic but highly spontaneous with energy surplus of above $73 \mathrm{~kJ} / \mathrm{mol}$. So, the deficit in the bimolecular step is being compensated for by the surplus in the unimolecular consecutive step. Also, the second step is found to be the rate determining step, as presented in Table 10.<smiles>Cc1ccc(C(=O)NNC(N)=O)cc1</smiles>

Figure 9. General scheme for the mechanism of reaction between $p$-methylbenzaldehyde and semicarbazide.

DFT B3LYP (6-311+G**) calculated thermodynamic parameters for reaction between

Table 9 p-methylbenzaldehyde and semicarbazide.

\begin{tabular}{ccccccc}
\hline Steps & $\begin{array}{c}\Delta S_{\text {reaction }}^{\#} \\
\left(\mathrm{Jmol}^{-1} \mathrm{~K}^{-1}\right)\end{array}$ & $\begin{array}{c}\Delta H_{\text {reaction }}^{\#} \\
\left(\mathrm{kJmol}^{-1}\right)\end{array}$ & $\begin{array}{c}\Delta G_{\text {reaction }}^{\#} \\
\left(\mathrm{kJmol}^{-1}\right)\end{array}$ & $\begin{array}{c}\Delta S_{\text {reaction }}^{o} \\
\left(\mathrm{Jmol}^{-1} \mathrm{~K}^{-1}\right)\end{array}$ & $\begin{array}{c}\Delta H_{\text {reaction }}^{o} \\
\left(\mathrm{kJmol}^{-1}\right)\end{array}$ & $\begin{array}{c}\Delta G_{\text {reaction }}^{o} \\
\left(\mathrm{kJmol}^{-1}\right)\end{array}$ \\
\hline $\begin{array}{c}\mathrm{A}+\mathrm{B} \rightleftharpoons \mathrm{TSI} \\
\mathrm{A}+\mathrm{B} \rightarrow \mathrm{INT}\end{array}$ & -234.54 & -23.12 & +46.81 & & & +28.53 \\
$\mathrm{INT} \rightleftharpoons \mathrm{TS} \mathrm{II}$ & +8.52 & +280.45 & +277.91 & -242.36 & -43.73 \\
$\mathrm{INT} \rightarrow \mathrm{P} 1+\mathrm{P} 2$ & & & & +238.25 & -1.90 & -72.93 \\
\hline
\end{tabular}

Table 10

DFT B3LYP (6-311+G**) calculated activation energy $\left(E_{a}\right)$, frequency factor $(A)$, rate constant $(k)$ and equilibrium constant $(K)$ for reaction between $p$-methylbenzaldehyde and semicarbazide.

\begin{tabular}{|c|c|c|c|c|c|c|}
\hline Steps & $\begin{array}{c}E_{a} \\
\left(\mathrm{kJmol}^{-1}\right) \\
\end{array}$ & $A$ & $\begin{array}{c}k_{2} \\
\left(d m^{3} \mathrm{~mol}^{-1} \mathrm{~s}^{-1}\right)\end{array}$ & $K_{2}$ & $k_{1}\left(s^{-1}\right)$ & $K_{1}$ \\
\hline $\mathrm{A}+\mathrm{B} \rightleftharpoons \mathrm{TSI}$ & +68.79 & $25.77 \mathrm{dm}^{3} \mathrm{~mol}^{-1} \mathrm{~s}^{-1}$ & & $2.18 \times 10^{-8}$ & & \\
\hline $\mathrm{A}+\mathrm{B} \rightarrow \mathrm{INT}$ & & & $3.92 \times 10^{4}$ & & & \\
\hline $\mathrm{INT} \rightleftharpoons \mathrm{TS}$ II & +183.26 & $4.70 \times 10^{13} \mathrm{~s}^{-1}$ & & & & $5.99 \times 10^{12}$ \\
\hline $\mathrm{INT} \rightarrow \mathrm{P} 1+\mathrm{P} 2$ & & & & & $1.28 \times 10^{-36}$ & \\
\hline
\end{tabular}




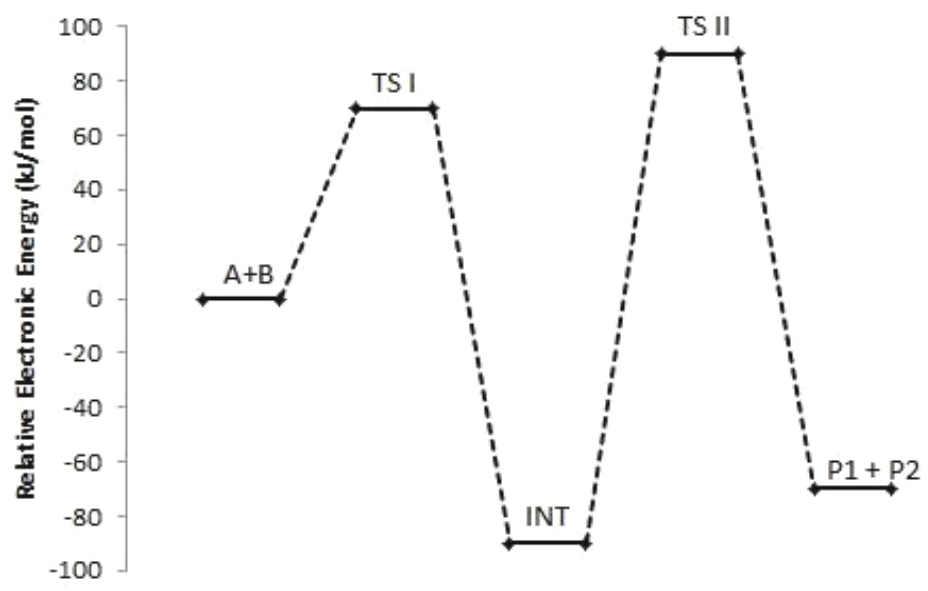

Figure 10. Diagram of relative electronic energies along the channels of the reaction between $p$-methylbenzaldehyde and semicarbazide.

\section{Reaction between o-hydroxybenzaldehyde and semicarbazide}

The computed mechanism of formation of (E)-2-(2-hydroxybenzylidene)hydrazinecarboxamide and water from $o$-hydroxybenzaldehyde and semicarbazide is presented in Figure 1. Figure 12 presents the schematic diagram of the electronic energy of the reaction mechanism. Tables 11 and 12, respectively, present thermodynamic and kinetic data for this reaction mechanism.

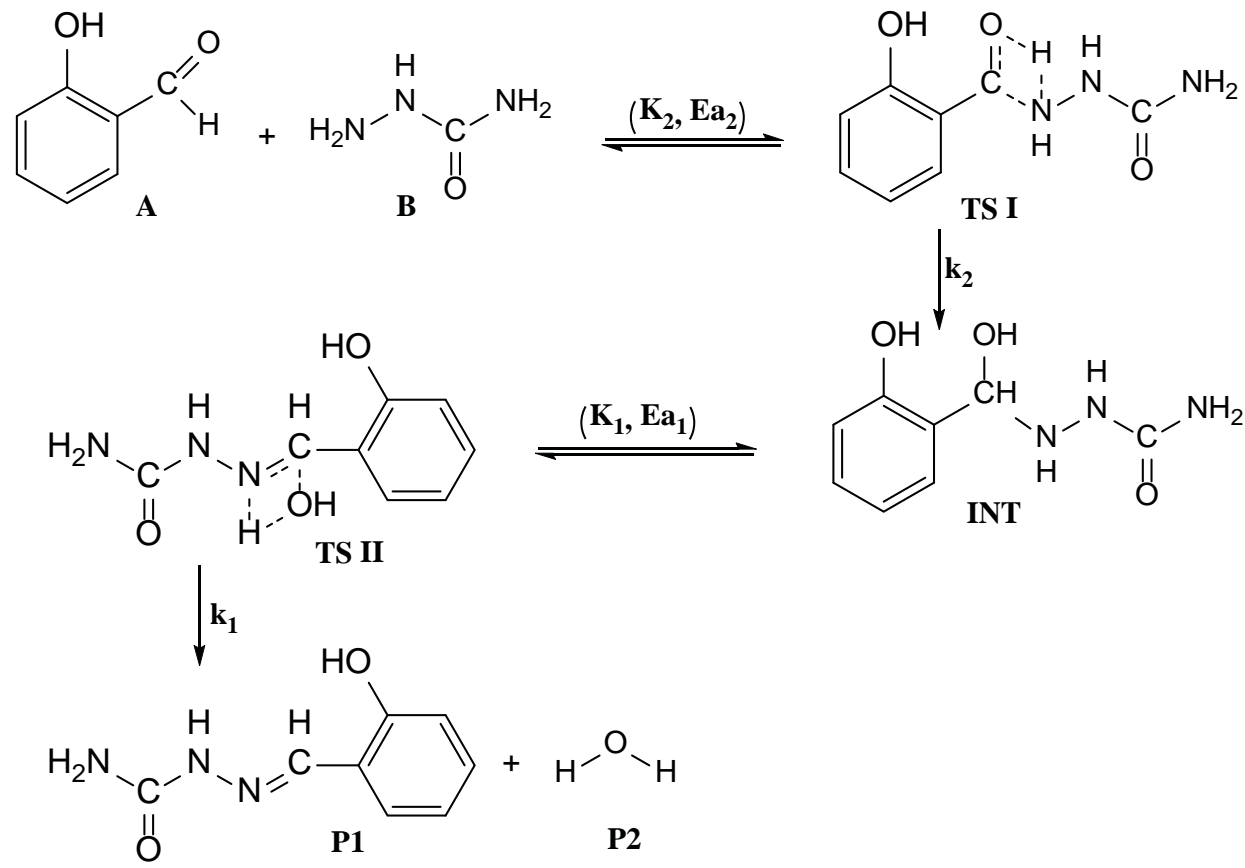

Figure 11. General scheme for the mechanism of reaction between $o$-hydroxybenzaldehyde and semicarbazide.

DFT B3LYP (6-311+G**) calculated thermodynamic parameters for reaction between o-hydroxybenzaldehyde and semicarbazide.

\begin{tabular}{|c|c|c|c|c|c|c|}
\hline Steps & $\begin{array}{c}\Delta S_{\text {reaction }}^{\#} \\
\left(\mathrm{Jmol}^{-1} \mathrm{~K}^{-1}\right)\end{array}$ & $\begin{array}{l}\Delta H_{\text {reaction }}^{\#} \\
\left(\mathrm{kJmol}^{-1}\right)\end{array}$ & $\begin{array}{l}\Delta G_{\text {reaction }}^{\#} \\
\left(\mathrm{kJmol}^{-1}\right)\end{array}$ & $\begin{array}{c}\Delta S_{\text {reaction }}^{o} \\
\left(\mathrm{Jmol}^{-1} \mathrm{~K}^{-1}\right)\end{array}$ & $\begin{array}{l}\Delta H_{\text {reaction }}^{o} \\
\left(\mathrm{kJmol}^{-1}\right)\end{array}$ & $\begin{array}{l}\Delta G_{\text {reaction }}^{o} \\
\left(\mathrm{kJmol}^{-1}\right)\end{array}$ \\
\hline $\mathrm{A}+\mathrm{B} \rightleftharpoons \mathrm{TSI}$ & -196.39 & -22.75 & +35.80 & & & \\
\hline $\mathrm{A}+\mathrm{B} \rightarrow \mathrm{INT}$ & & & & -204.96 & -43.59 & +17.52 \\
\hline $\mathrm{INT} \rightleftharpoons \mathrm{TS} \mathrm{II}$ & -6.69 & +25.68 & +27.67 & & & \\
\hline $\mathrm{INT} \rightarrow \mathrm{P} 1+\mathrm{P} 2$ & & & & +135.74 & +109.03 & +68.56 \\
\hline
\end{tabular}


DFT B3LYP (6-311+G**) calculated activation energy $\left(E_{a}\right)$, frequency factor $(A)$, rate constant $(k)$ and equilibrium constant $(K)$ for reaction between $o$-hydroxybenzaldehyde and semicarbazide.

\begin{tabular}{|c|c|c|c|c|c|c|}
\hline Steps & $\begin{array}{c}E_{a} \\
\left(\mathrm{kJmol}^{-1}\right)\end{array}$ & $A$ & $\begin{array}{c}k_{2} \\
\left(d m^{3} \mathrm{~mol}^{-1} \mathrm{~s}^{-1}\right)\end{array}$ & $K_{2}$ & $\begin{array}{c}k_{1} \\
\left(s^{-1}\right) \\
\end{array}$ & $K_{1}$ \\
\hline $\mathrm{A}+\mathrm{B} \rightleftharpoons \mathrm{TSI}$ & +60.91 & $2.53 \times 10^{3} \mathrm{dm}^{3} \mathrm{~mol}^{-1} \mathrm{~s}^{-1}$ & & $8.53 \times 10^{-4}$ & & \\
\hline $\mathrm{A}+\mathrm{B} \rightarrow \mathrm{INT}$ & & & $3.32 \times 10^{6}$ & & & \\
\hline $\mathrm{INT} \rightleftharpoons \mathrm{TS}$ II & +257.04 & $2.08 \times 10^{20} \mathrm{~s}^{-1}$ & & & & $9.39 \times 10^{-13}$ \\
\hline $\mathrm{INT} \rightarrow \mathrm{P} 1+\mathrm{P} 2$ & & & & & $6.05 \times 10^{00}$ & \\
\hline
\end{tabular}

After computing the first transition step we found that it is exothermic and non-spontaneous with somewhat high activation energy to overcome. It has an energy deficit of about $74 \mathrm{~kJ} / \mathrm{mol}$. The collision factor of this step is less, in comparison with that of the second transition step. The unimolecular transition step is endothermic (from enthalpy of activation) and non-spontaneous (from Gibbs energy of activation), with very high activation barrier. The energy requirements for this step are found to be in the neighbourhood of $300 \mathrm{~kJ} / \mathrm{mol}$, suggestive of energy supply to sustain the reaction. However, the pre-exponential factor of the step seems to indicate otherwise. The first bimolecular step has an appreciable amount of energy released to the system, as compared to Gibbs energy required for the step to be spontaneous and hence, the reaction is expected to proceed in the presented direction easily. Meanwhile, the unimolecular consecutive step appears to be highly demanding as it is computed to be highly endothermic and non-spontaneous. For this step to be feasible external energy intake is actually a necessity and the step is calculated to be the rate determining step.

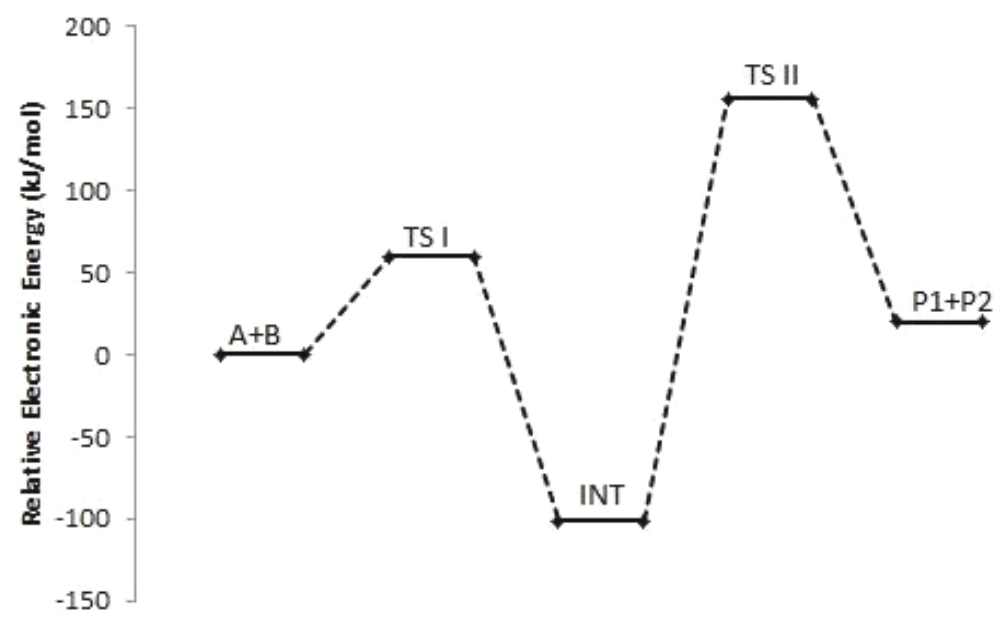

Figure 12. Energy profile for reaction between o-hydroxylbenzaldehyde and semicarbazide.

\section{General mechanism and rate law of the reaction of synthesis of semicarbazones}

From all the general reaction schemes given above, the reaction mechanism consists of the following steps:

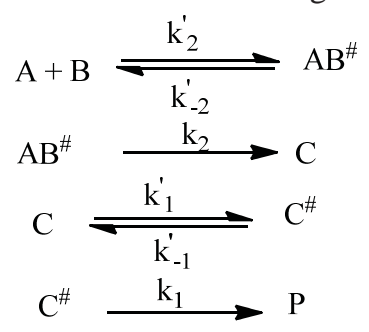

The rate laws for all the products of the reaction can be written as follows:

$$
\begin{aligned}
& \frac{d[P]}{d t}=k_{1}\left[C^{\#}\right] \\
& \frac{d\left[C^{\#}\right]}{d t}=-k_{1}\left[C^{\#}\right]-k_{-1}^{\prime}\left[C^{\#}\right]+k_{1}^{\prime}[C]
\end{aligned}
$$




$$
\begin{aligned}
& \frac{d[C]}{d t}=-k_{1}^{\prime}[C]+k_{-1}^{\prime}\left[C^{\#}\right]+k_{2}\left[A B^{\#}\right] \\
& \frac{d\left[A B^{\#}\right]}{d t}=-k_{2}\left[A B^{\#}\right]-k_{-2}^{\prime}\left[A B^{\#}\right]+k_{2}^{\prime}[A][B]
\end{aligned}
$$

Using steady state approximation, from Eq.(7)

$$
\left[C^{\#}\right]=\frac{k_{1}^{\prime}}{k_{1}+k_{-1}^{\prime}}[C]
$$

Using Eq.(8) and Eq.(10), we have

$$
[C]=\frac{k_{2}\left(k_{1}+k_{-1}^{\prime}\right)\left[A B^{\#}\right]}{k_{1}^{\prime} k_{1}}
$$

Similarly, from Eq.(9), we have

$$
\left[A B^{\#}\right]=\frac{k_{2}^{\prime}}{k_{2}+k_{-2}^{\prime}}[A][B]
$$

Eq.(11) and Eq.(12) yield:

$$
[C]=\frac{k_{2} k_{2}^{\prime}\left(k_{1}+k_{-1}^{\prime}\right)}{k_{1}^{\prime} k_{1}\left(k_{2}+k_{-2}^{\prime}\right)}[A][B]
$$

From Eq.(13) and Eq.(10), we have

$$
\left[C^{\#}\right]=\frac{k_{2} k_{2}^{\prime}}{\left(k_{2}+k_{-2}^{\prime}\right)}[A][B]
$$

Therefore, the overall rate law can be written as:

$$
\frac{d[P]}{d t}=\frac{k_{2} k_{2}^{\prime}}{\left(k_{2}+k_{-2}^{\prime}\right)}[A][B]
$$

where $\frac{k_{2} k_{2}^{\prime}}{\left(k_{2}+k_{-2}^{\prime}\right)}=K^{\prime}$, experimental rate constant.

\section{Conclusions}

According to the obtained results, some steps in the semicarbazones's formation mechanisms were found to require energy input, while in other steps huge amount of energy was released to the system, and the energy barriers were not too high, thus making the reaction thermodynamically feasible on the whole. The mechanisms of the reaction were found to consist of two transition states (bi- and unimolecular), in some of the mechanisms the first bimolecular step was computed to be the rate determining step, while in others it was the unimolecular step that determines the reaction pace. Furthermore, the substituent position (ortho-, para- and meta-) significantly influenced the reaction feasibility: paraand meta- positions enhanced the reaction, ortho- position was noted to have negatively influenced the reaction, leading to endothermic reaction, as observed in the case of interaction between ortho-hydroxybenzaldehyde and semicarbazide. Kinetically, the rate constant values of the examined reaction mechanisms were also found to be unambiguous.

\section{References}

1. Williamson, K.L. Macroscale and Microscale Organic Experiments, 3rd ed. Boston: Houghton-Mifflin, 1999, 426 p.

2. Cerecetto, H.; González, M. Current Topics in Medicinal chemistry, Chemotherapy of chagas’ disease: status and new development. Current Topics in Medicinal Chemistry, 2002, 2, pp. 1185-1190.

3. Micale, N.; Zappala, M.; Zuccala, G.; Menniti, F.S.; Ferreri, G.; De Sarro, G.; Grasso, S. Synthesis of 2-semicarbazonomethyl-4,5- methylenedioxyphenylacetic acids as anticonvulsant agents. Farmaco, 2005, 60, pp. 231-235. 
4. Yogeeswari, P.; Sriram, D.; Thirumurugan, R.; Raghavendran, J.V.; Sudhan, K.; Pavana, R.K.; Stables, J.P. Discovery of N-(2,6- Dimethylphenyl)-Substituted Semicarbazones as Anticonvulsants: Hybrid PharmacophoreBased Design. Journal of Medicinal Chemistry, 2005, 48, pp. 6202-6211.

5. Mishra, V.; Pandeya, S.N. Analgesic activity and hypnotic effect of ( \pm )-3-mentone semicarbazone and thiosemicarbazone derivatives. Acta Pharmaceutica, 2001, 51, pp. 183- 188.

6. Singhal, M.; Paul, A.; Singh, H.P.; Dubey, S.K.; Gaur, K. Evaluation of reducing power assay of chalcone semicarbazones. Journal of Chemical and Pharmaceutical Research, 2011, 3, pp. 639-645.

7. Rajasekaran, S.; GopalKrishna R.; Sanjay Pai, P.N.; Gurpreet, S.S. Synthesis, Antibacterial and in vitro Antioxidant Activity of 2,3-Substituted Quinazolin-4(3H)-ones. Journal of Chemical and Pharmaceutical Research, 2010, 2, pp. 482-488.

8. Dimmock, J.R.; Puthucode, R.N.; Smith, J.M.; Hetherington, M.; Quail, J.W.; Pugazhenthi, U.; Lechler, T.; Stables, J.P. (Aryloxy)aryl semicarbazones and related compounds: A novel class of anticonvulsant agents possessing high activity in the maximal electroshock screen. Journal of Medicinal Chemistry, 1996, 39, pp. 3984-3997.

9. Pandeya, S.N.; Mishra, V.; Singh, P.N.; Rupainwar, D.C. Anticonvulsant activity of thioureido derivatives of acetopheononesemicarbazones. Pharmacological Research, 1998, 37, pp.17-22.

10. Pandeya, S.N.; Mishra, V.; Ponnilavarasan, I.; Stables, J.P. Anticonvulsant activity of p-chlorophenyl substituted arylsemicarbazones - the role of primary terminal amino group. Polish Journal of Pharmacology, 2000, 52, pp. 283-290.

11. Pandeya, S.N.; Sowmayalakshmi, V.; Panda, S.S.; Pandey, A.; Stable, J.P. Anticonvulsant activity of semicarbazone derivatives of Mannich bases. Indian Journal of Chemistry, 2003, 42, pp. 2657- 2661.

12. Engel, T.; Reid, P. Physical Chemistry. Pearson Prentice Hall: New York, 2006, 924 p. 